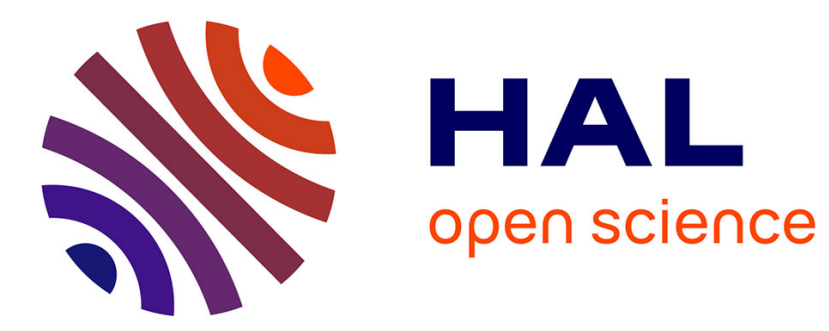

\title{
Fast Warming of the Surface Ocean Under a Climatological Scenario
}

\author{
Q. Jamet, W. K Dewar, N. Wienders, B. Deremble
}

\section{To cite this version:}

Q. Jamet, W. K Dewar, N. Wienders, B. Deremble. Fast Warming of the Surface Ocean Under a Climatological Scenario. Geophysical Research Letters, 2019, 46 (7), pp.3871-3879. 10.1029/2019GL082336 . hal-02410290

\section{HAL Id: hal-02410290 \\ https://hal.science/hal-02410290}

Submitted on 13 Dec 2019

HAL is a multi-disciplinary open access archive for the deposit and dissemination of scientific research documents, whether they are published or not. The documents may come from teaching and research institutions in France or abroad, or from public or private research centers.
L'archive ouverte pluridisciplinaire HAL, est destinée au dépôt et à la diffusion de documents scientifiques de niveau recherche, publiés ou non, émanant des établissements d'enseignement et de recherche français ou étrangers, des laboratoires publics ou privés. 


\title{
Fast warming of the surface ocean under a climatological scenario
}

\author{
Q. Jamet ${ }^{1 *}$, W. K. Dewar ${ }^{1}$, N. Wienders ${ }^{1}$ and B. Deremble ${ }^{2}$ \\ ${ }^{1}$ Department of Earth, Ocean and Atmospheric Science, the Florida State University, Tallahassee, Florida \\ ${ }^{2}$ Laboratoire de Météorologie Dynamique, Paris, France
}

\section{Key Points:}

- Weakly varying climatological winds reduce upper ocean vertical mixing, affecting the redistribution of air-sea fluxes

- Coupled to an atmospheric boundary layer, the modeled ocean response to climatological winds is to warm up considerably at the surface

- Results illustrate the pivotal improvements in air-sea interactions achieved by driving an ocean model with an atmospheric boundary layer

*The Florida State University, 117 N Woodward Avenue, Tallahassee, FL 32306-4320.

Corresponding author: Quentin Jamet, qjamet@fsu.edu 


\section{Abstract}

We examine various strategies for forcing ocean-only models, including an atmospheric boundary layer model. This surface forcing allows air-sea exchanges to affect atmospheric temperature and relative humidity, thus removing the assumption of an infinite atmospheric heat capacity associated with the prescription of these variables. When exposed to climatological winds, the simulated North Atlantic oceanic temperature warms considerably at the surface as compared to a model with full atmospheric variability. This warming is mainly explained by a weakened upper ocean vertical mixing in response to the weakly varying climatological winds. Specifying the atmospheric temperatures inhibits this warming, but depends on the unrealistic large atmospheric heat capacity. We thus interpret the simulated warmer ocean as a more physically consistent ocean response. We conclude the use of an atmospheric boundary layer model provides many benefits for ocean only modeling, although a 'normal' year strategy is required for maintaining high frequency winds.

\section{Introduction}

The ocean is one of the most important components of the climate system due to its large heat capacity. Understanding its dynamics remains challenging due to interactions with the other components of the climate system, particularly the atmosphere. It is common to decouple the climate system to reduce its complexity: A well known strategy is to use ocean-only numerical simulations for which air-sea interactions are control variables that one can adjust to study the ocean responses. However this approach strongly relies on parameterizations used to represent these interactions. We study here oceanonly models driven by different surface forcing strategies with the view toward assessing strengths and weaknesses of each.

Modeling a variable ocean under a specified but variable atmosphere is a useful and efficient idealization. However, some studies have highlighted an important caveat of this approach. Huck and Vallis (2001) have found that large scale modes of variability (Colin de Verdière and Huck, 1999; Huck et al., 1999) only appear if the ocean model was forced by prescribed fluxes rather than a prescribed atmosphere. In the first case (prescribed air-sea fluxes), the ocean is not as constrained as in the second case where the atmospheric conditions maintain the ocean in a state close to the forcing conditions. Additionally, Rahmstorf and Willebrand (1995) have shown that large scale ocean feedbacks on the 
atmospheric temperature have significant impacts on the rate of the overturning circulation in the North Atlantic. Such feedbacks are not considered when the ocean surface is restored toward prescribed atmospheric conditions. These results illustrate the limitations associated with a prescribed atmospheric forcing, where the assumption of an infinite heat capacity for the atmosphere interferes with the development of internal ocean dynamics.

Following these ideas, we wish to assess if similar limitations would be at work for the development of an oceanic state of equilibrium under climatological winds. This question arises from the recognized contribution of the fast varying winds associated with synoptic weather systems to maintain realistic turbulent air-sea fluxes (Gulev, 1994; Hughes et al., 2012; Jung et al., 2014; Ponte and Rosen, 2004; Wu et al., 2016; Zhai et al., 2012) and upper ocean vertical mixing (Condron and Renfrew, 2013; Holdsworth and Myers, 2015; Wu et al., 2016). This high frequency atmospheric variability is indeed filtered out by the averaging used to construct climatological products, such that the high frequency wind variance strongly reduces at mid- and high latitudes (Fig. 1, top panels). Forcing an ocean model with climatological winds is therefore expected to significantly modify air-sea fluxes and upper ocean vertical mixing. It is however less clear how the ocean will adjust to such a forcing if thermodynamic ocean feedbacks on the atmosphere are considered.

To identify the oceanic state that develops under climatological winds, we propose to work with an atmospheric boundary layer (CheapAML; Deremble et al., 2013). With this strategy, the assumption of an infinite atmospheric heat capacity is relaxed and atmospheric temperature and humidity can respond to ocean surface structures. A detailed description of the model strategy is given in Section 2. The ocean response to climatological winds in this framework is described in Section 3. We compare these results with those obtained with a more traditional representation of air-sea fluxes, i.e. when the atmosphere is prescribed, in Section 4, and assess the relevance of a 'normal' year to maintain high frequency winds in Section 5. Finally, we conclude and discuss the results in Section 6 . 


\section{Numerical Experiments}

We use the MIT general circulation model (MITgcm; Marshall et al., 1997) in a regional configuration of the North Atlantic: the domain extends from $20^{\circ} \mathrm{S}$ to $55^{\circ} \mathrm{N}$ with a horizontal resolution of $\frac{1}{4}^{\circ}$ (see Supporting Information). The mixed layer depth computed by the non-local K-Profile Parametrization (KPP) scheme of Large et al. (1994) is used in the heat budget of Section 3.2.

At the surface, different strategies are used to force the ocean model and look at their impact on the ocean dynamics. In a first set of experiments, we couple the ocean model to the atmospheric boundary layer model CheapAML (Deremble et al., 2013). With this approach, we better represent the air-sea exchanges, and we also let the ocean develop its internal dynamics (not necessarily correlated to a prescribed atmospheric state). In CheapAML, winds are assumed to be the least sensitive atmospheric variable to ocean surface structure, and are thus prescribed. The remaining atmospheric variables, i.e. temperature and humidity, are advected by these prescribed winds and are modified by the air-sea fluxes. Over the ocean, the temporal evolution of these atmospheric variables is computed using a forced advection-diffusion equation. Over land, temperature and humidity are strongly relaxed toward the reanalysis prescribed values. The atmospheric variables prescribed in CheapAML are applied every 6 hours and derived from the Drakkar forcing set (cf Supporting Information).

This configuration is run for 10 years in three different experiments. In the first one, referred to as AML_FULL, we use the full range of atmospheric time scales, from sub-daily (6-hourly) to interannual, over the period 1958-1967. In the second one, referred to as AML_CLIM, we use a yearly repeated climatological atmospheric seasonal cycle. To consistently filter the year-to-year atmospheric variability, the climatology has been computed as an ensemble average of all the years between 1958-1977. This second experiment is run for 10 years, i.e. for the same duration as the first experiment. In the third experiment, referred to as AML_NY, we use a yearly repeated 'normal' year forcing (Large and Yeager, 2004), constructed as the realistic atmospheric forcing from $\mathrm{Au}-$ gust 2003 to July 2004. This experiment is run for 5 years only. Initial conditions are common to all experiments, and are derived from a $\frac{1}{12}^{\circ}$ global ocean-only simulation (cf Supporting Information). 
To understand how the atmospheric temperature and humidity in CheapAML responds to the ocean surface dynamics, two additional experiments are conducted where all atmospheric variables (wind, atmospheric surface air temperature and humidity) are prescribed. This strategy is commonly used in the ocean modeling community and it will serve as a reference test case to which we will compare our experiments. With these prescribed atmospheric variables, we compute the air-sea fluxes the same way as the previous cases but there is no feedback on the atmospheric temperature and humidity. As in AML_FULL and AML_CLIM we run two experiments with either fully varying or climatological winds. We name these two experiments FORC_FULL and FORC_CLIM, respectively.

\section{Fully Varying vs Climatological Wind Experiments}

Because the Sea Surface Temperature (SST) is an oceanic variable sensitive to airsea exchange, we first compare the model SST for the two experiments AML_CLIM and AML_FULL (Fig. 2, top panels) after 10 years of simulation. The yearly averaged SST differences between the two experiments are very large in amplitude, reaching more than $8^{\circ} \mathrm{C}$ in the subtropical gyre, and spreading over the North Atlantic, north of $20^{\circ} \mathrm{N}$. At the center of the subtropical gyre where the largest SST differences are observed, the time evolution of SST over the course of the 10 years of simulation reveals that such large differences are reached quickly, after 5 months, suggesting a fast dynamic response of the ocean. The mechanism that drives the warming of the subtropical gyre in the AML_CLIM experiment is described in the two following sections. We focus on the first two years of simulation where most of the differences build up.

\subsection{Heat Fluxes}

In our configuration, the components of the net heat fluxes which vary from experiment to experiment are the latent and sensible fluxes, as well as the outgoing longwave radiation associated with the SST (the other components are prescribed). We discuss their respective contribution for the net heat fluxes in the following.

In AML_FULL, the time mean and standard deviation of the latent and sensible heat fluxes (computed over the 10 years of simulation) are $117 \pm 37$ and $8 \pm 8 \mathrm{~W} \mathrm{~m}^{-2}$, respectively. Added together, these fluxes are sufficiently strong to induce positive (up- 
ward) net heat fluxes during the first two months of simulation (Fig. 3, top panel). They contribute to the cooling of the ocean surface at the beginning of the simulation which is consistent with winter time (January-February). In AML_CLIM, the turbulent fluxes are reduced by more than $50 \%\left(57 \pm 19 \mathrm{~W} \mathrm{~m}^{-2} ; 1 \pm 1.4 \mathrm{~W} \mathrm{~m}^{-2}\right.$ for latent and sensible heat fluxes, respectively), consistent with earlier results (Hughes et al., 2012). As a consequence, the too weak turbulent heat fluxes lead to negative (downward) net heat fluxes, contributing to the warming of the surface ocean at the beginning of the simulation (top right panel of Fig. 2).

The mechanisms that drive the reduction in turbulent air-sea fluxes are further investigated by looking at the sensible heat flux amplitude $S=\rho_{A} C_{p}^{(A)}|\mathbf{u}|\left(S S T-T_{a}-\right.$ $\gamma h)$, with $\rho_{A}=1.3 \mathrm{~kg} \mathrm{~m}^{-3}, C_{p}^{(A)}=1004 \mathrm{~J} \mathrm{~kg}^{-1} \mathrm{~K}^{-1}, \gamma=0.0098 \mathrm{~K} \mathrm{~m}^{-1}$ the dry atmospheric adiabatic lapse rate and $h=10 \mathrm{~m}$ the height at which turbulent air-sea fluxes are computed. Fig. 3 (right panel) show the sensible heat as a function of the two main contributing factors, i.e. the scalar wind speed $|\mathbf{u}|$ and the air-sea temperature difference $\left(S S T-T_{a}\right)$. As a response to a weaker wind variance in AML_CLIM, there are no winds stronger than $5 \mathrm{~m} \mathrm{~s}^{-1}$ (top right panel). However, for wind speed weaker than $5 \mathrm{~m} \mathrm{~s}^{-1}$, the sensible heat fluxes in AML_CLIM remain weaker than those obtained under fully varying winds, suggesting that the changes in air-sea fluxes are not only driven by the weaker climatological wind speed $|\mathbf{u}|$. The other parameter that contributes to the strength of the sensible heat fluxes is the air-sea temperature difference $S S T-T_{a}$. In AML_CLIM, the air-sea temperature differences do not exceed $\pm 1^{\circ} \mathrm{C}$ (Fig. 3, bottom right panel), while they range from about $-2^{\circ} \mathrm{C}$ to about $+4{ }^{\circ} \mathrm{C}$ in AML_FULL. Under fully varying winds, there are thus oceanic processes that take the ocean surface away from the overlying atmosphere and lead to larger air-sea temperature differences. We show in Section 3.2 that those processes are associated with upper ocean vertical mixing.

As the ocean surface quickly warms up at the beginning of the simulation when exposed to climatological winds, the outgoing longwave radiation increases accordingly (outgoing longwave radiation is proportional to $S S T^{4}$ ). The system reaches a new state after 5 months with a new $\mathrm{SST}$ about $8^{\circ} \mathrm{C}$ warmer than for the fully varying wind experiment. The upward longwave radiation is $40-50 \mathrm{~W} \mathrm{~m}^{-2}$ stronger in the climatological wind experiment, which balances about $80 \%$ of the $-60 \mathrm{~W} \mathrm{~m}^{-2}$ time mean difference in turbulent heat fluxes induced by the weakly varying climatological winds. The net airsea heat fluxes are of comparable amplitude in the two experiments, preventing the SST 
difference to be much larger than $8^{\circ} \mathrm{C}$. After the 5 months of initial transition, the model slowly drifts toward its new state of equilibrium with an SST trend of about $+0.25^{\circ} \mathrm{C} / \mathrm{yr}$. Note that since atmospheric downward longwave radiations are prescribed, the radiative effects of a warmer atmosphere are not considered. Such an effect would positively contribute to the upper ocean warming since increased downward longwave atmospheric radiations would induce larger warming of the ocean surface (Fig. S3).

\subsection{Oceanic Vertical Mixing}

We now describe the differences between the two equilibria in terms of oceanic dynamics. We performed a heat budget following Peter et al. (2006) for the box at the center of the subtropical gyre where the SST difference is the largest. The temperature tendency $\partial_{t}\langle T\rangle$ within the mixed layer $h(x, y, t)$ (computed by the KPP parameterization) is decomposed into advective terms, a flux term and dissipation terms (cf Supporting Information). Comparing the results of this heat budget for the two experiments using CheapAML (Fig. S5), the most important difference in the processes controlling the temperature is found to be the upper ocean vertical mixing.

While the upper ocean vertical mixing is relatively constant through the year in AML_CLIM with a mixed layer depth which does not exceed $15 \mathrm{~m}$, it exceeds $40 \mathrm{~m}$ in AML_FULL during winter in response to atmospheric storms. Thus, even though the net heat fluxes in AML_CLIM are weaker (cf Section 3.1), their contribution for the heat budget of the mixed layer quickly exceed $0.5{ }^{\circ} \mathrm{C} /$ day. In AML_FULL by contrast, surface heat fluxes warm a thicker mixed layer, and thus lead to a weaker temperature tendency during the first 5 months of simulation (Fig. S5, top right panel). Also note that, in AML_FULL, the vertical diffusion at the bottom of the mixed layer $\left.\frac{1}{h} K_{z} \partial_{z} T\right|_{z=-h}$ controls most of the balance between surface heating and internal ocean processes, i.e. it explains a significant fraction of the residual $\partial_{t}\langle T\rangle+\frac{Q_{n e t}}{\rho_{0} C_{p} h}$ (Fig. S5, bottom panels). The other terms (lateral diffusion, advective and entrainment terms; cf Eq. (4) in Supporting Information) are at least one order of magnitude smaller. In AML_CLIM by contrast, the vertical diffusion at the bottom of the mixed layer is weaker and explains a smaller fraction of that residual. This suggests that the oceanic processes within the mixed layer have changed. We suspect night time convection comes into play, but we cannot draw firm conclusions with the 5-day averaged outputs used in this study. 
The large reduction in mixed layer depth in AML_CLIM is observed all over the domain, where the maximum depth of the mixed layer computed by the KPP parameterization is about 3 to 4 times shallower North of $20^{\circ} \mathrm{N}$ (Fig. 1, bottom panels). This spatial pattern resembles the wind variance (top panels). In fact, in AML_FULL, the high frequency wind variance induces a vertical velocity shear $\partial_{z} \mathbf{u}$ in the upper layers, that destabilizes the ocean: the Richardson number $R_{i}=\frac{N^{2}}{\partial_{z} \mathbf{u}}$ (with $N^{2}$ the buoyancy frequency) decreases, and ultimately falls below the critical value $R_{i}^{\text {crit. }}=0.3$ used in our configuration. The vertical structure of the ocean is thus unstable to Kelvin-Helmholz shear instability, the leading process driving ocean vertical mixing for such low $R_{i}$ (Mack and Schoeberlein, 2004). In AML_CLIM by contrast, the vertical velocity shear is much weaker in response to the weaker high frequency variance of the climatological winds, and the ocean is more stable. If less mixing occurs in the upper ocean, the surface heat fluxes induce a fast warming of the upper ocean.

\section{A Prescribed Atmosphere}

Most numerical studies that use climatological atmospheric fields do not use an atmosphere boundary layer model to compute the atmospheric temperature and humidity (Grégorio et al., 2015; Penduff et al., 2011; Sérazin et al., 2015). In order to compare our results with these kind of experiments, we perform two additional runs (FORC_FULL and FORC_CLIM) for which all atmospheric fields (including temperature and humidity) are prescribed. After 10 years, the simulated SST difference between FORC_FULL and FORC_CLIM share a relatively similar spatial pattern with the AML experiments (Fig. 2, left panels), but those differences are much weaker, and do not exceed $2.5^{\circ} \mathrm{C}$ in the subtropical gyre. Note that, consistent with the temperature difference observed between the two AML experiments, the SST difference observed in the subtropical gyre is also reached after only 5 months of simulation (Fig. 2, right panels).

From these comparisons, we conclude that prescribing the atmospheric state reduces the effects of climatological winds on the temperature of the upper ocean layers. The underlying physical basis remains however questionable. Due to the weak high frequency variance of the climatological winds, the vertical ocean mixing remains weak. The difference in the mixed layer depth computed by the KPP scheme is very similar to what is shown in Fig. 1 for the AML experiments. As a consequence, the upper ocean tends 
to warm up in FORC_CLIM, but the atmosphere does not. In fact, because the atmospheric temperature is prescribed in this experiment, the ocean-atmosphere temperature differences increase, as shown in Fig. 3 (bottom right panel) for the subtropical gyre. In FORC_CLIM, the $S S T-T_{a}$ difference is always positive and roughly $2-4^{\circ} \mathrm{C}$. This illustrates the damping role of the atmosphere on the surface ocean temperatures, constraining the upper ocean warming tendency. This increased $S S T-T_{a}$ difference counteracts the effect of climatological winds on the turbulent air-sea fluxes, such that for the same wind speed amplitude, the sensible heat fluxes are much larger in FORC_CLIM than in AML_CLIM and always positive (Fig. 3, top right panel). A similar scenario happens for the latent heat fluxes, which results in turbulent heat fluxes in FORC_CLIM which are of comparable amplitude than those found in FORC_FULL (Fig. 3, bottom left panel). This is not consistent with previous studies (Gulev, 1994, 1997; Hughes et al., 2012), where the lack of high frequency wind variance is expected to significantly reduce the magnitude of turbulent air-sea fluxes. In the AML experiments by contrast, since the atmospheric temperature follows the surface ocean warming we have shown that the reduced turbulent heat fluxes under climatological winds are consistently captured and balanced by increased outgoing longwave radiations. Since this latter scenario has better physical consistency, we argue that the dynamically consistent ocean response to an artificial climatological atmosphere is to warm considerably at the surface.

\section{A view toward ocean climate studies}

To study the oceanic variability and to distinguish between the atmospherically forced and the internally generated low-frequency oceanic variability, it is common to drive ocean models with climatological winds. When using an atmospheric boundary layer, our results reveal that fast varying atmospheric winds have to be accounted for in order to maintain a realistic oceanic state. Results of the AML_NY experiment driven by a 'normal' year forcing (Large and Yeager, 2004) are promising in this respect. Both air-sea turbulent fluxes and the depth of the mixed layer compare well to those diagnosed in AML_FULL (not shown). This results in smaller differences in SST between the two experiments (Fig. S2 and S3) compared to those obtained with climatological winds. The oceanic state that develops under a 'normal' year forcing is thus more consistent with the oceanic state that develops under a fully varying forcing. This is likely to make the comparison between 
the two experiments more relevant for the attribution of the origin of low-frequency oceanic variability.

For long time scales, where the ocean is expected to control air-sea exchanges (Bjerknes, 1964; Gulev et al., 2013; Jungclaus and Koenigk, 2010; Latif et al., 2006; Shaffrey and Sutton, 2006), there are potential benefits in using an atmospheric boundary layer model to drive ocean-only models. The simulations presented here are however too short to make any statement about low-frequency variability with good accuracy. To illustrate this idea, we have performed an exploratory 50 years, high resolution $\left(1 / 12^{\circ}\right)$ run in a regional configuration (same ocean model formulation coupled to CheapAML and driven by the same 'normal' year forcing). In this high resolution experiment, atmospheric temperatures computed by the atmospheric boundary layer model exhibit variability at time scales longer than one year (Fig. S4, left panel). This low-frequency atmospheric variability is particularly strong downstream of Cape Hatteras and along the North Atlantic current (Fig. S4, right panel). This is indicative of a low-frequency atmospheric variability driven by ocean processes which is obviously missing when atmospheric temperatures are prescribed with a seasonally repeating cycle. Such a low-frequency atmospheric variability feeds back onto the ocean, enhancing SST variability at low frequency. This is illustrated on Fig. S4 (right panel), where yearly averaged SST standard deviation is compared between this high resolution simulation and a companion simulation driven by prescribed 'normal' year atmospheric forcing. Although this feedback weakens SST variability in localized regions, the low-frequency SST variability is larger almost all over the domain with a pattern that largely replicates the pattern indicated by atmospheric temperature variations. Along the North Atlantic current, this increase is of about $+0.3-0.4^{\circ} \mathrm{C}$ and contributes to $20-30 \%$ of the $\sim 1.5^{\circ} \mathrm{C}$ total SST low-frequency variability of this region. These preliminary results are very encouraging and highlight the benefits of using an atmospheric boundary layer model to drive ocean-only models in the context of climate studies. It could for instance bring new insights to the ongoing debate on the origin of North Atlantic climate variability (Clement et al., 2015; Farneti, 2017; Zhang et al., 2016). 


\section{Conclusion}

We have revisited the surface forcing strategy used to drive ocean-only models. The analysis of an ocean model in a regional North Atlantic configuration coupled to an atmospheric boundary layer model shows that the oceanic state that develops under climatological winds is much warmer at the surface than the one that develops in a companion experiment driven by fully varying winds. It is up to $8^{\circ} \mathrm{C}$ warmer in the North Atlantic subtropical gyre after only 5 months of simulation. Although significantly different than realistic conditions, we argue that those changes are physically consistent, and interpret this new oceanic state as likely when exposed to an artificial climatological atmosphere. This surface warming is the result of a side effect of climatological averaging on winds where fast varying synoptic weather systems are filtered out, strongly reducing upper ocean vertical mixing and turbulent air-sea fluxes. These results illustrate the key role played by thermodynamical ocean feedbacks on the atmosphere for the development of an oceanic state of equilibrium.

In the climatological scenario, the system reaches a new balance for which the warmer ocean surface induced by weak ocean vertical mixing is balanced by increased outgoing longwave radiation. This balance is quite different from the equilibrium reached in the traditional approach (where the atmospheric state is prescribed). In the latter case, the ocean vertical mixing remains weak, but the effects of the climatological winds on the turbulent air-sea fluxes are balanced by an increased contribution of the difference between the warming ocean and the prescribed atmosphere. The turbulent air-sea fluxes are strengthened and the atmosphere controls the surface ocean dynamics by damping the surface warming tendency. However, this 'traditional' approach relies on the unrealistic assumption of an infinite heat capacity for the atmosphere, whereas the ocean is more appropriately approximated as the slow climate component since its heat capacity is much larger than that of the atmosphere. Those results suggest that the use of an atmospheric boundary layer model rather than a prescribed atmosphere when decoupling an ocean model from the atmosphere is a more suitable strategy to better represent the physics of the air-sea interactions.

To isolate the oceanic dynamics from the low-frequency atmospheric forcing when an ocean model is coupled to an atmospheric boundary layer model, one thus needs a wind product that does not contain any interannual and longer variability but which ac- 
counts for the fast varying winds. Last, a preliminary experiment driven by a 'normal' year strategy (Large and Yeager, 2004) exhibits promising results: The oceanic state that develops under such a forcing stays in better agreement with the fully varying experiment, and atmospheric temperatures exhibit low-frequency variability which feeds back onto ocean surface dynamics. We conclude that, combined with a normal year forcing strategy, the use of an atmospheric boundary layer to drive ocean-only models for climate oriented studies is very attractive.

\section{Acknowledgments}

We thank Camille Lique for a constructive discussion and references. We thank Bernard Barnier and its collaborators for providing us the Drakkar Forcing Sets data and the expertise for using them. This work was supported by NSF Grant OCE-1537304. Data used in this study are available at http://ocean.fsu.edu/ qjamet/share/data/clim_wind _GRL2019/.

\section{References}

Barrier, N., Treguier, A.-M., Cassou, C., and Deshayes, J. (2013). Impact of the winter north-atlantic weather regimes on subtropical sea-surface height variability. Climate dynamics, 41(5-6), 1159-1171.

Bjerknes, J. (1964). Atlantic air-sea interaction. Advances in geophysics, 10(1), 182.

Brodeau, L., Barnier, B., Treguier, A.-M., Penduff, T., and Gulev, S. (2010). An era40-based atmospheric forcing for global ocean circulation models. Ocean Modelling, 31(3-4), 88-104.

Chassignet, E. P., and Xu, X. (2017). Impact of horizontal resolution (1/12 to 1/50) on gulf stream separation, penetration, and variability. Journal of Physical Oceanography, 47(8), 1999-2021.

Clement, A., Bellomo, K., Murphy, L. N., Cane, M. A., Mauritsen, T., Rädel, G., and Stevens, B. (2015). The atlantic multidecadal oscillation without a role for ocean circulation. Science, 350(6258), 320-324.

Colin de Verdière, A., and Huck, T. (1999). Baroclinic instability: An oceanic wavemaker for interdecadal variability. J. Phys. Oceanogr., 29(5), 893-910.

Condron, A., and Renfrew, I. A. (2013). The impact of polar mesoscale storms on 
northeast Atlantic Ocean circulation. Nature Geoscience, 6(1), 34.

Deremble, B., Wienders, N., and Dewar, W. (2013). Cheapaml: A simple, atmospheric boundary layer model for use in ocean-only model calculations. Mon. Wea. Rev., 141(2), 809-821.

Dussin, R., and Barnier, B. (2013). The making of DFS 5.1. Drakkar Project Rep. [available online at http://www.drakkar-ocean.eu/publications/reports/dfs5-1report].

Dussin, R., Barnier, B., Brodeau, L., and Molines, J. (2016). The making of the drakkar forcing set dfs5. DRAKKAR/MyOcean Rep. 01-04, 16.

Fairall, C., Bradley, E. F., Hare, J., Grachev, A., and Edson, J. (2003). Bulk parameterization of air-sea fluxes: Updates and verification for the coare algorithm. J. Clim., 16(4), 571-591.

Farneti, R. (2017). Modelling interdecadal climate variability and the role of the ocean. Wiley Interdisciplinary Reviews: Climate Change, 8(1).

Gent, P. R., and McWilliams, J. C. (1990). Isopycnal mixing in ocean circulation models. J. Phys. Oceanogr., 20(1), 150-155.

Grégorio, S., Penduff, T., Sérazin, G., Molines, J.-M., Barnier, B., and Hirschi, J. (2015). Intrinsic variability of the atlantic meridional overturning circulation at interannual-to-multidecadal time scales. Journal of Physical Oceanography, 45(7), 1929-1946.

Gulev, S. K. (1994). Influence of space-time averaging on the ocean-atmosphere exchange estimates in the north atlantic midlatitudes. J. Phys. Oceanogr., 24(6), $1236-1255$.

Gulev, S. K. (1997). Climatologically significant effects of space-time averaging in the north atlantic sea-air heat flux fields. Journal of climate, 10(11), 27432763.

Gulev, S. K., Latif, M., Keenlyside, N., Park, W., and Koltermann, K. P. North Atlantic Ocean control on surface heat flux on multidecadal timescales. Nature, 499(7459), 464-467.

Holdsworth, A. M., and Myers, P. G. (2015). The influence of high-frequency atmospheric forcing on the circulation and deep convection of the Labrador Sea. $J$. Clim., 28(12), 4980-4996.

Huck, T., Colin de Verdière, A., and Weaver, A. J. (1999). Interdecadal variability 
of the thermohaline circulation in box-ocean models forced by fixed surface fluxes. J. Phys. Oceanogr., 29(5), 865-892.

Huck, T., and Vallis, G. K. (2001). Linear stability analysis of three-dimensional thermally-driven ocean circulation: application to interdecadal oscillations. Tellus, 53A, 526-545.

Hughes, P. J., Bourassa, M. A., Rolph, J. J., and Smith, S. R. (2012). Averagingrelated biases in monthly latent heat fluxes. J. Atmos. Ocean. Technol., 29(7), 974-986.

Jung, T., Serrar, S., and Wang, Q. (2014). The oceanic response to mesoscale atmospheric forcing. Geophys. Res. Lett., 41(4), 1255-1260.

Jungclaus, J. H., and Koenigk, T. (2010). Low-frequency variability of the arctic climate: the role of oceanic and atmospheric heat transport variations. Clim. Dyn., $34(2-3), 265-279$.

Large, W. G., McWilliams, J. C., and Doney, S. C. (1994). Oceanic vertical mixing: A review and a model with a nonlocal boundary layer parameterization. Rev. Geophys., 32(4), 363-403.

Large, W. G., and Yeager, S. G. (2004). Diurnal to decadal global forcing for ocean and sea-ice models: the data sets and flux climatologies.

Latif, M., Böning, C., Willebrand, J., Biastoch, A., Dengg, J., Keenlyside, N., ... Madec, G. (2006). Is the thermohaline circulation changing? J. Clim., 19(18), 4631-4637.

Mack, S. A., and Schoeberlein, H. C. (2004). Richardson number and ocean mixing: Towed chain observations. Journal of Physical Oceanography, 34(4), 736-754.

Marshall, J., Adcroft, A., Hill, C., Perelman, L., and Heisey, C. (1997). A finitevolume, incompressible Navier Stokes model for studies of the ocean on parallel computers. J. Geophys. Res., 102(C3), 5753-5766.

Molines, J.-M., Barnier, B., Penduff, T., Treguier, A., and Le Sommer, J. (2014). Orca12. 146 climatological and interannual simulations forced with dfs4. 4: Gjm02 and mjm88. drakkar group experiment rep (Tech. Rep.).

GDRIDRAKKAR-2014-03-19, 50 pp.[Available online at http://www. drakkar-ocean. eu/publications/reports/orca12_reference_experiments_2014.].

Penduff, T., Juza, M., Barnier, B., Zika, J., Dewar, W. K., Treguier, A.-M., ... Audiffren, N. (2011). Sea level expression of intrinsic and forced ocean variabilities 
at interannual time scales. J. Clim., 24(21), 5652-5670.

Peter, A.-C., Le Hénaff, M., Du Penhoat, Y., Menkes, C. E., Marin, F., Vialard, J., ... Lazar, A. (2006). A model study of the seasonal mixed layer heat budget in the equatorial atlantic. Journal of Geophysical Research: Oceans, $111(\mathrm{C} 6)$.

Ponte, R. M., and Rosen, R. D. (2004). Nonlinear effects of variable winds on ocean stress climatologies. J. Clim., 17(6), 1283-1293.

Rahmstorf, S., and Willebrand, J. (1995). The role of temperature feedback in stabilizing the thermohaline circulation. J. Phys. Oceanogr., 25(5), 787-805.

Redi, M. H. (1982). Oceanic isopycnal mixing by coordinate rotation. J. Phys. Oceanogr., $12(10), 1154-1158$.

Sérazin, G., Penduff, T., Grégorio, S., Barnier, B., Molines, J.-M., and Terray, L. (2015). Intrinsic variability of sea level from global ocean simulations: Spatiotemporal scales. J. Clim., 28(10), 4279-4292.

Shaffrey, L., and Sutton, R. (2006). Bjerknes compensation and the decadal variability of the energy transports in a coupled climate model. J. Clim., 19(7), $1167-1181$.

Wu, Y., Zhai, X., and Wang, Z. (2016). Impact of synoptic atmospheric forcing on the mean ocean circulation. J. Clim., 29(16), 5709-5724.

Zhai, X., Johnson, H. L., Marshall, D. P., and Wunsch, C. (2012). On the wind power input to the ocean general circulation. J. Phys. Oceanogr., 42(8), 13571365.

Zhang, R., Sutton, R., Danabasoglu, G., Delworth, T. L., Kim, W. M., Robson, J., and Yeager, S. G. (2016). Comment on the atlantic multidecadal oscillation without a role for ocean circulation. Science, 352(6293), 1527-1527. 

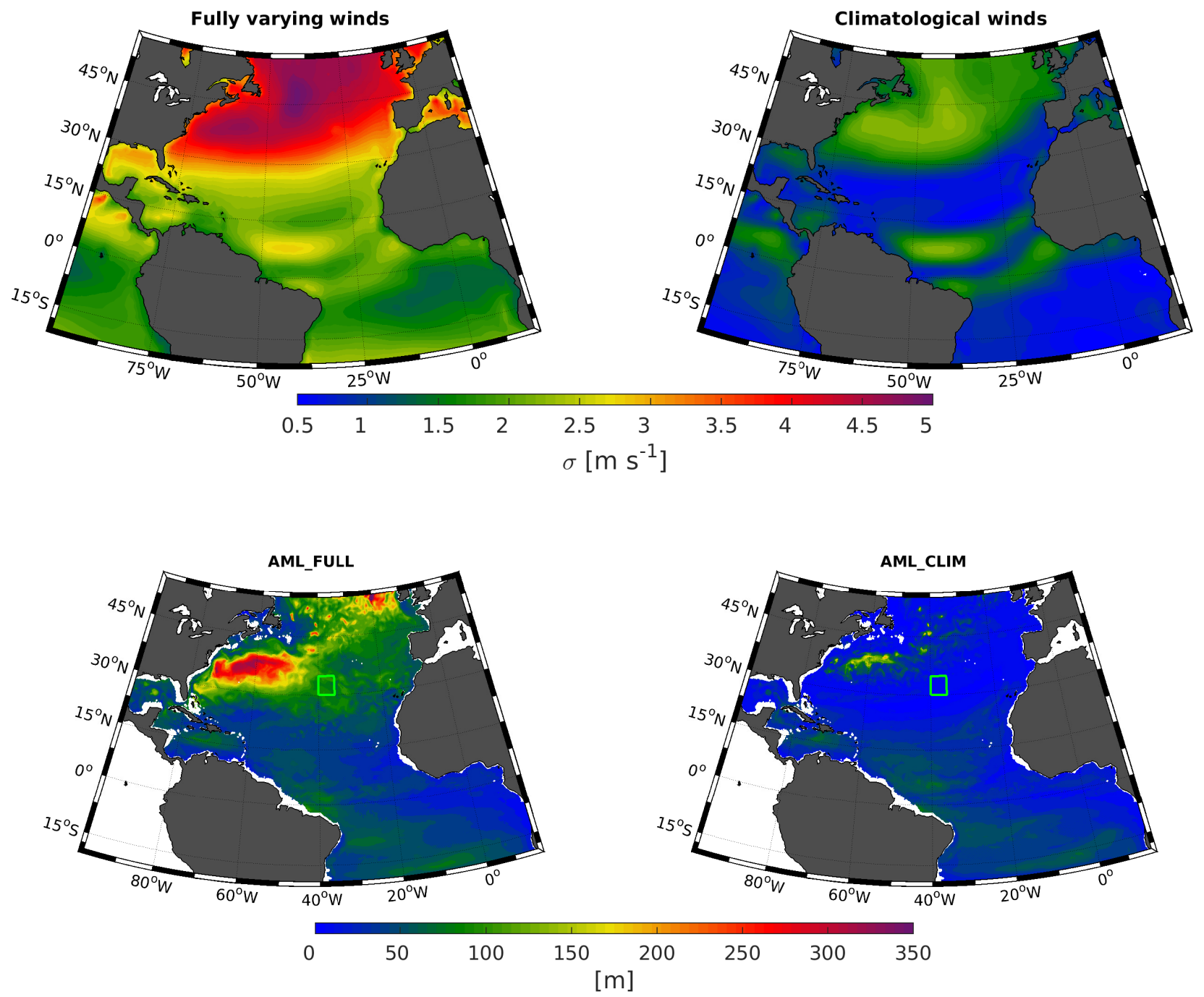

Figure 1. (Top) Seasonal standard deviation $\sigma\left[\mathrm{m} \mathrm{s}^{-1}\right]$ of the wind speed $\|u\|=\sqrt{u^{2}+v^{2}}$ for the fully varying (left) and the climatological (right) winds. (Bottom) Maximum depth of the mixed layer $[\mathrm{m}]$ computed by the KPP parameterization during the first year of simulation for the AML_FULL (left) and the AML_CLIM (right) experiments. 

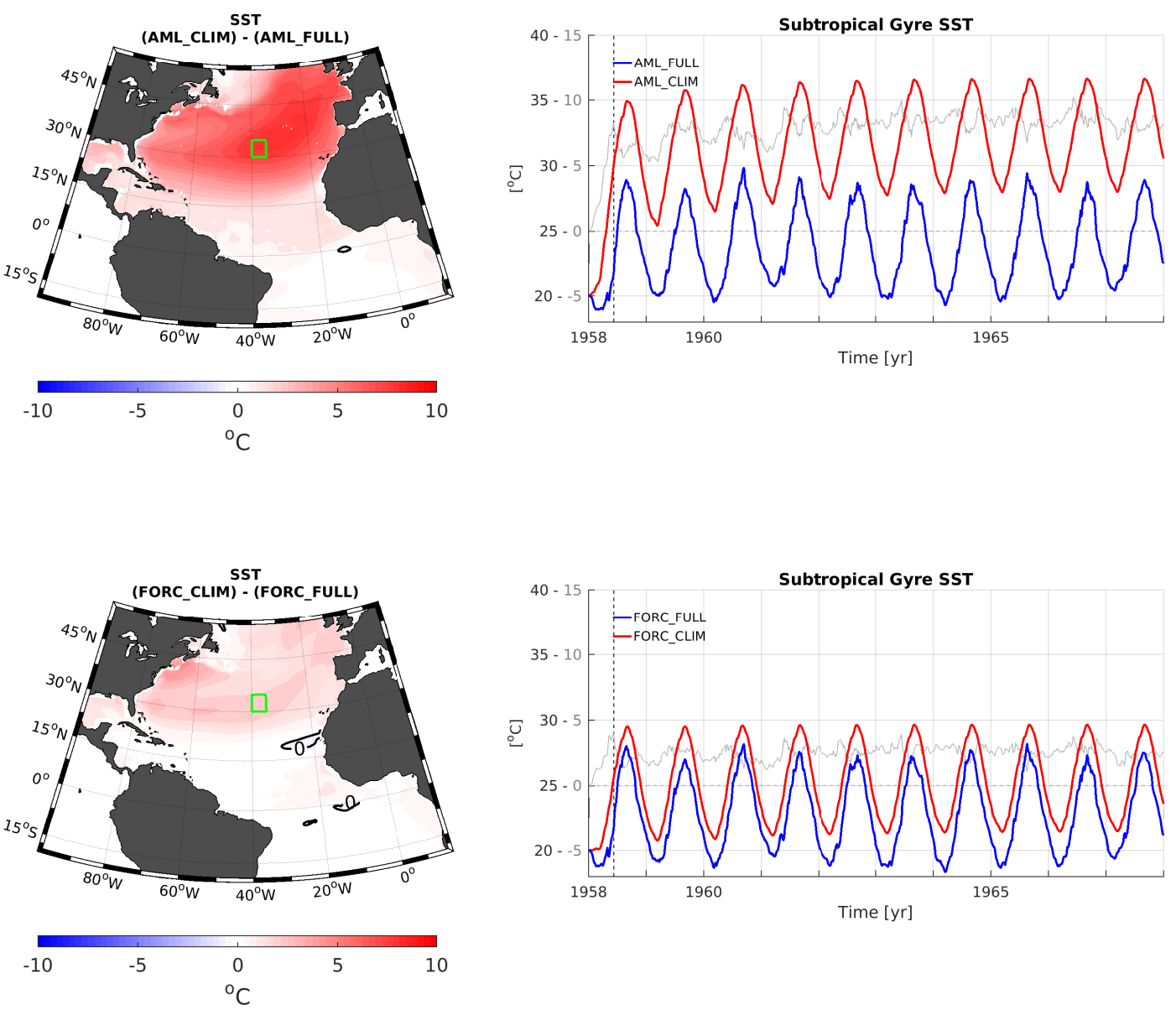

Figure 2. (Top) Yearly averaged SST difference between the AML_CLIM and the AML_FULL experiment for the last year of simulation, i.e. 1967 (left), and (right) associated time series of the spatially averaged SST in the subtropical gyre ([40-35W;30-35N], green box on the left panel). The gray line is the difference between the two experiments, with the associated scale on the left in gray. (Bottom) Same as top panels, but for the FORC experiments. 

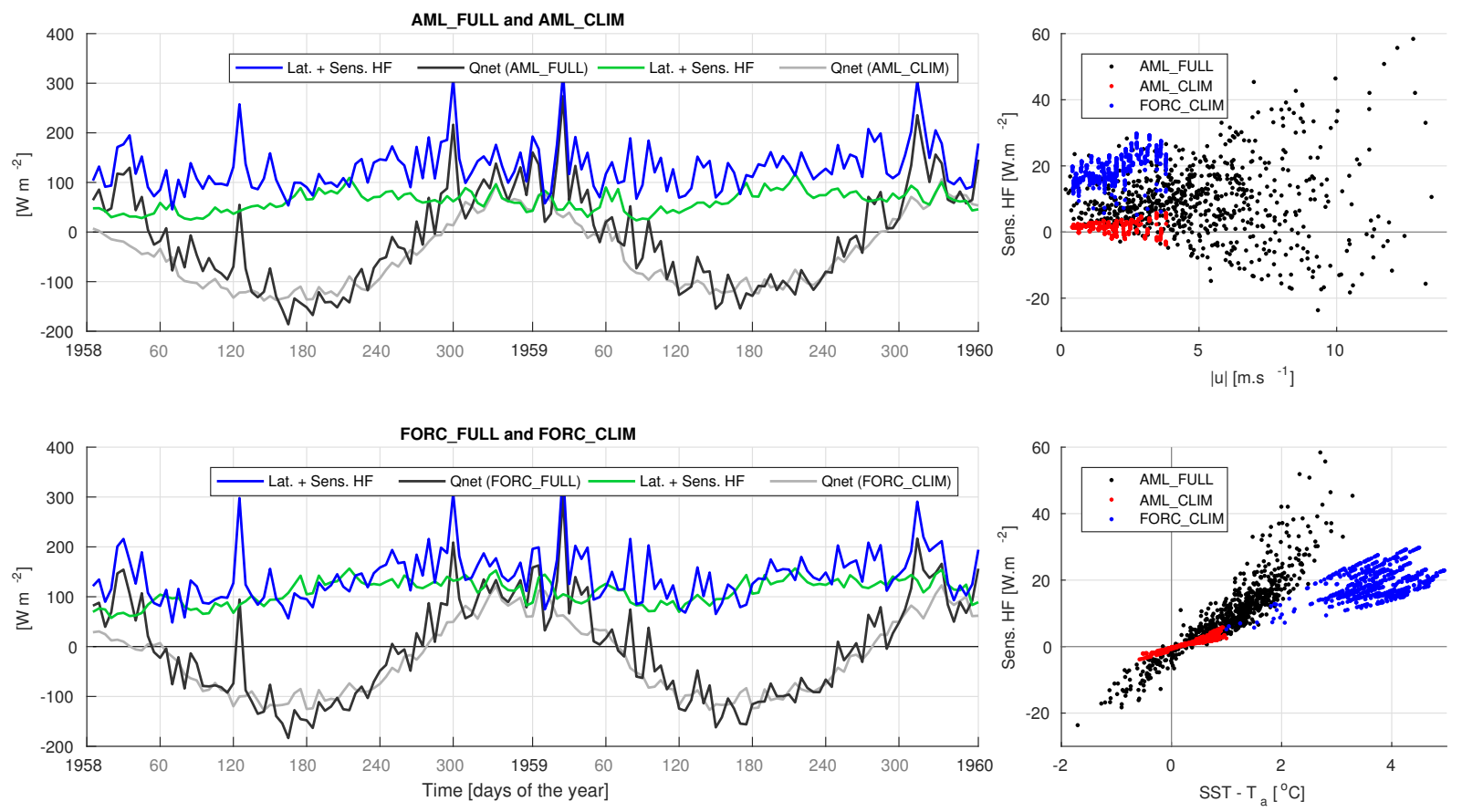

Figure 3. (Top left) Spatially averaged net heat fluxes $Q_{n e t}$ (positive upward, [W $\left.\mathrm{m}^{-2}\right]$ ) at the center of the subtropical gyre (green box of Fig. 2) for the AML_FULL (dark gray line) and the AML_CLIM (light gray line) experiments, and the associated contribution of the latent plus sensible heat fluxes (blue and green lines, respectively). (Bottom left) Same as top left panel but for the FORC experiments. (Right) Scatter plots of the sensible heat fluxes as a function of the wind speed (top) and the air-sea temperature difference SST-T $a$ (bottom) for AML_FULL (black), AML_CLIM (red) and FORC_CLIM (blue). Data correspond to the 10 years long time series at a point within the subtropical gyre (green box of Fig. 2) and are not sensitive to which point is chosen. 